OPEN ACCESS

Edited by:

LiZuo,

Ohio State University, USA

Reviewed by:

Robin Lewis Cooper, University of Kentucky, USA

Brenda Schoffstall,

Barry University, USA

Zewen Liu,

Wuhan University, China

*Correspondence:

Jonathan M. Peake

jonathan.peake@qut.edu.au

Specialty section:

This article was submitted to Striated Muscle Physiology,

a section of the journal

Frontiers in Physiology

Received: 13 October 2016 Accepted: 06 February 2017 Published: 07 March 2017

Citation:

Singh DP, Barani Lonbani Z, Woodruff MA, Parker TJ, Steck R and

Peake JM (2017) Effects of Topical Icing on Inflammation, Angiogenesis,

Revascularization, and Myofiber Regeneration in Skeletal Muscle

Following Contusion Injury.

Front. Physiol. 8:93.

doi: 10.3389/fphys.2017.00093

\section{Effects of Topical lcing on Inflammation, Angiogenesis, Revascularization, and Myofiber Regeneration in Skeletal Muscle Following Contusion Injury}

\author{
Daniel P. Singh ${ }^{1}$, Zohreh Barani Lonbani ${ }^{1}$, Maria A. Woodruff ${ }^{2}$, Tony J. Parker ${ }^{1,3}$, \\ Roland Steck ${ }^{4}$ and Jonathan M. Peake ${ }^{1,3 *}$
}

${ }^{1}$ Tissue Repair and Regeneration Group, Institute of Health and Biomedical Innovation, Queensland University of Technology, Brisbane, QLD, Australia, ${ }^{2}$ Biofabrication and Tissue Morphology Group, Institute of Health and Biomedical Innovation, Queensland University of Technology, Brisbane, QLD, Australia, ${ }^{3}$ School of Biomedical Sciences, Queensland University of Technology, Brisbane, QLD, Australia, ${ }^{4}$ Medical Engineering Research Facility, Queensland University of Technology, Brisbane, QLD, Australia

Contusion injuries in skeletal muscle commonly occur in contact sport and vehicular and industrial workplace accidents. Icing has traditionally been used to treat such injuries under the premise that it alleviates pain, reduces tissue metabolism, and modifies vascular responses to decrease swelling. Previous research has examined the effects of icing on inflammation and microcirculatory dynamics following muscle injury. However, whether icing influences angiogenesis, collateral vessel growth, or myofiber regeneration remains unknown. We compared the effects of icing vs. a sham treatment on the presence of neutrophils and macrophages; expression of CD34, von Willebrands factor (vWF), vascular endothelial growth factor (VEGF), and nestin; vessel volume; capillary density; and myofiber regeneration in skeletal after muscle contusion injury in rats. Muscle tissue was collected 1, 3, 7, and $28 \mathrm{~d}$ after injury. Compared with uninjured rats, muscles in rats that sustained the contusion injury exhibited major necrosis, inflammation, and increased expression of CD34, VWF, VEGF, and nestin. Compared with the sham treatment, icing attenuated and/or delayed neutrophil and macrophage infiltration; the expression of VWF, VEGF, and nestin; and the change in vessel volume within muscle in the first $7 d$ after injury $(P<0.05)$. By contrast, icing did not influence capillary density in muscle $28 \mathrm{~d}$ after injury $(P=0.59)$. The percentage of immature myofibers relative to the total number of fibers was greater in the icing group than in the sham group $28 \mathrm{~d}$ after injury $(P=0.026)$, but myofiber cross-sectional area did not differ between groups after $7 \mathrm{~d}(P=0.35)$ and $28 \mathrm{~d}(P=0.30)$. In conclusion, although icing disrupted inflammation and some aspects of angiogenesis/revascularization, these effects did not result in substantial differences in capillary density or muscle growth.

Keywords: muscle injury, cryotherapy, regeneration, inflammation, angiogenesis 


\section{INTRODUCTION}

Closed soft tissue trauma or contusion injuries in skeletal muscle are relatively common among athletes (Canale et al., 1981; Volpi et al., 2004) and industrial workers (Dement and Lipscomb, 1999). These types of injuries typically occur when a sudden, heavy, compressive force is applied to the muscle and are therefore common in contact sports (Jarvinen et al., 2005). Contusion injuries are clinically manifested by localized pain, swelling, reduced range of motion, and tenderness to palpation (Kary, 2010). At the molecular level, contusion injuries result in transient necrosis, infiltration of inflammatory cells, and expression of proinflammatory cytokines. These processes are followed by the formation of new myofibers and subsequent myofiber maturation (Merrick et al., 1999; Lee et al., 2005; Schaser et al., 2006, 2007; Carvalho et al., 2010; Puntel et al., 2011; Takagi et al., 2011; Vieira Ramos et al., 2016).

The process of muscle healing begins soon after injury and involves phases of tissue destruction, repair, and remodeling. These phases involve regeneration of myofibers, formation of connective scar tissue, angiogenesis, and vascularization (Jarvinen et al., 2005; Ceafalan et al., 2015). Angiogenesis is a key process in muscle regeneration after injury (Ochoa et al., 2007; Miyazaki et al., 2011; Huey et al., 2016). Successful muscle regeneration depends on restoration of the vascular network required for the exchange of oxygen and nutrients, and the formation of mature muscle fibers (Rhoads et al., 2009). Following injury, angiogenesis is tightly coordinated with the proliferation, differentiation, and fusion of satellite cells to existing myofibers (Christov et al., 2007). Activated satellite cells accumulate and proliferate near capillaries and are stimulated to grow by various growth factors secreted by surrounding epithelial cells (Christov et al., 2007). Proliferating and differentiating satellite cells stimulate endothelial cells to join together to form nascent blood vessels (Christov et al., 2007) and microvascular fragments to form new sprouts (Rhoads et al., 2009). Angiogenesis in regenerating muscle tissue also depends on macrophages, chemokines such as monocyte chemotactic protein 1, and various growth factors and their receptors (Ochoa et al., 2007; Wagatsuma, 2007; Novak et al., 2011; Ceafalan et al., 2015).

A variety of options are used to treat muscle injuries including: immobilization/remobilization; rest, ice, compression, and elevation (RICE); ultrasound; hyperbaric oxygen therapy; anti-inflammatory or antifibrotic drugs; and treatment with platelet-rich plasma or muscle-derived stem cells. Icing is a mainstay treatment for many types of acute musculoskeletal injuries (Meeusen and Lievens, 1986). The general rationale for using ice to treat such injuries is to alleviate pain, reduce tissue metabolism, and modify vascular responses to restrict swelling (Swenson et al., 1996). A number of studies have investigated the effects of cryotherapy (e.g., icing or perfusion of cold saline) on muscle regeneration, inflammation, and oxidative stress after

\footnotetext{
Abbreviations: CT, computed tomography; HIF- $1 \alpha$, hypoxia-inducible factor $1 \alpha$; ROS, reactive oxygen species; vWF, von Willebrands factor; VEGF, vascular endothelial growth factor.
}

crush or contusion injuries (Merrick et al., 1999; Lee et al., 2005; Schaser et al., 2006, 2007; Carvalho et al., 2010; Puntel et al., 2011; Takagi et al., 2011; Vieira Ramos et al., 2016). Infusion of cold saline in injured skeletal muscle restores microvascular hemodynamics at $1 \mathrm{~h}$ (Schaser et al., 2006) and $24 \mathrm{~h}$ (Schaser et al., 2007) after injury.

To date, no research has investigated whether cryotherapy influences angiogenesis during the later phases of muscle growth/regeneration (i.e., $>1 \mathrm{~d}$ after injury). It is important to understand how icing influences angiogenesis in skeletal muscle following injury for two reasons. First, icing is a common treatment for muscle injuries. Second, angiogenesis is closely linked with muscle repair. Evidence from other tissue types suggests that hypothermia can alter the secretion of vascular endothelial growth factor (VEGF) (Coassin et al., 2010; Takeyama et al., 2015) and angiogenesis (Kuo et al., 2010; Kao et al., 2011). It remains unknown whether hypothermia exerts similar effects in skeletal muscle tissue.

The aim of this study was to examine the effects of icing soon after muscle contusion injury on subsequent inflammation, angiogenesis, vessel volume, and myofiber regeneration. We hypothesized that icing would attenuate inflammation, angiogenesis, and changes in vessel volume, which may slow myofiber regeneration.

\section{MATERIALS AND METHODS}

The experimental procedures in this project were approved by the Queensland University of Technology Animal Ethics Committee (ethics approval number 11-318). The experiments were conducted in accordance with the Australian Code of Practice for the Care and Use of Animals for Scientific Purposes (National Health and Medical Research Council, 2013).

\section{Experimental Overview}

The time course of experimental procedures is outlined in Figure 1. Ninety adult male Wistar strain rats (12 weeks old) were acquired from Animal Resources Centre (Canning Vale, WA, Australia). Adult rats were chosen to minimize any growth effects on muscle tissue regeneration during the weeks following injury. Eighty rats were divided randomly into an icing group or a sham group ( $n=40$ per group). Both groups of animals were subjected to a contusion muscle injury, after which icing or a sham treatment was applied to the skin covering the injury site. The rats in each group were sacrificed at four separate time points: $1,3,7$, and $28 \mathrm{~d}$ after injury ( $n=10$ per group at each time point). Ten rats were used as uninjured and untreated controls.

\section{Muscle Contusion Injury}

Anesthesia was induced before injury by placing the rat in an induction chamber containing $5 \%$ isofluorane delivered in $2-$ $3 \mathrm{l} \mathrm{O}_{2} / \mathrm{min}$. Anesthesia was then maintained for at least 20 min after injury through a face mask that delivered $2-2.5 \%$ isofluorane in 1-1.5 $\mathrm{L} \mathrm{O}_{2} / \mathrm{min}$. This procedure was used so that the rats would not move while the ice or sham treatment was applied. Analgesia was achieved by subcutaneous injection of buprenorphine $(0.05 \mathrm{mg} / \mathrm{kg})$ immediately before injury and 


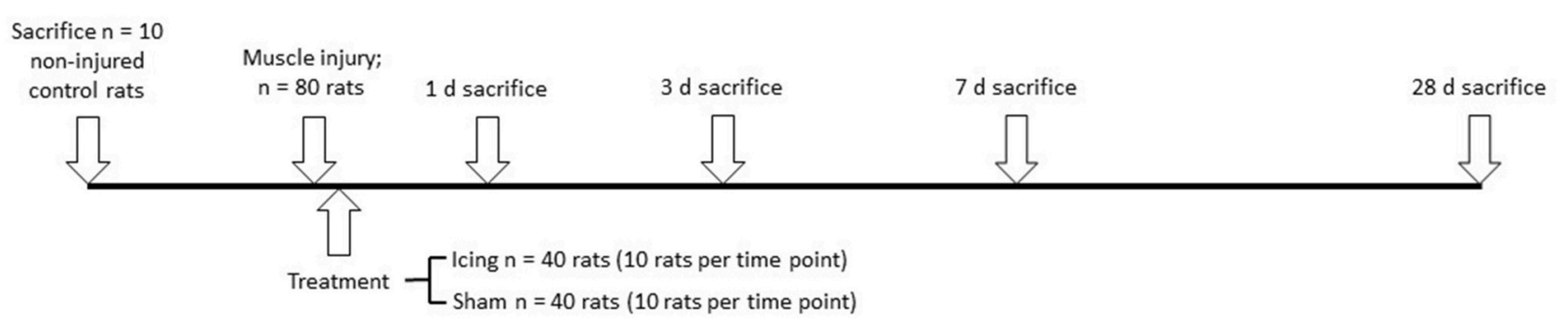

FIGURE 1 | Time course of experimental procedures. The uninjured control, icing, and sham treatment groups at each time of sacrifice were divided into groups of six rats for histology and immunohistochemistry, and four rats for micro-CT imaging.

administration of tramadol $(25 \mathrm{mg} / \mathrm{l})$ in the drinking water during the first $5 \mathrm{~d}$ after injury. These anesthetic and analgesic treatments may have induced the expression of key mediators of angiogenesis, such as hypoxia-inducible factor- $1 \alpha$ (HIF-1 $\alpha)$ and VEGF (Li et al., 2006; Singleton et al., 2006; Luk et al., 2012). However, because we administered these treatments to all of the experimental animals, any such effects were most likely similar between the icing and sham groups.

During pilot work, we established a noninvasive contusion injury model using a custom-designed device based on an approach described by Stratton et al. (1984) that has been used extensively in other research. This pilot work confirmed that this approach caused substantial muscle contusion without perforating the skin or fracturing the bones of the hind limb. The procedure involved placing a rat with its left hind limb in an extended position on a platform. A cylindrical $400 \mathrm{~g}$ weight was placed in a metal column at a height $1.66 \mathrm{~m}$ above the platform and held in place temporarily with a metal pin. The weight was released by pulling the pin from the column. The weight then dropped onto the hind limb of the rat specifically in the region of the biceps femoris muscle. In this way, the injury was localized to a specific region of interest between the tibial notch of the knee joint and the tibiofibula conjunction.

\section{Icing and Sham Treatment}

Icing treatment was administered based on the method described by Takagi et al. (2011). Five min after the contusion injury was induced and while the rat was still anesthetized, a 5-cm diameter cylindrical ice block was applied to the skin surrounding the injured muscle for $20 \mathrm{~min}$. The ice block was massaged in a "Figure 8" motion on the injured area without compression. The underside of the leg was rested on an ice pack. In the sham group, a 50-ml flat-bottomed beaker (maintained at room temperature) was used to massage the injured area and to simulate the movement of the ice block, also for $20 \mathrm{~min}$. These icing and sham treatments were applied once on the day of injury. Following icing or the sham treatment, the rats were free to move around their cages as they recovered from the muscle injury. At 1, 3, 7, or $28 \mathrm{~d}$ after injury, the rats were euthanized by $\mathrm{CO}_{2}$ asphyxiation.

\section{Histology and Immunohistochemistry}

Muscle biopsies from the biceps femoris muscle were fixed in $10 \%$ neutral buffered formalin for $1 \mathrm{~d}$, processed, and then embedded in paraffin wax (Thermo Excelsior Tissue Processor and paraffin embedding station, Thermo Fisher Scientific, USA). Transverse serial sections (5 $\mu \mathrm{m}$ thick) were cut using a microtome (Leica Biosystems RM2235, Sydney, Australia) and mounted on poly-L-lysine adhesion glass slides (Thermo Fisher Scientific, Brisbane, Australia). Sections between a depth of 50 and $250 \mu \mathrm{m}$ were used for analysis. Slides were stained with hematoxylin and eosin (H\&E, Sigma-Aldrich, Sydney, Australia) for qualitative histological analysis of muscle regeneration. For immunohistochemistry, the slides were deparaffinized, treated with $3 \% \mathrm{H}_{2} \mathrm{O}_{2}$ for $30 \mathrm{~min}$, and then blocked with $2 \%$ bovine serum albumin (BSA) for $60 \mathrm{~min}$. Heat-induced antigen retrieval was performed using trisodium citrate buffer (Sigma-Aldrich) for $40 \mathrm{~min}$ at $70^{\circ} \mathrm{C}$ in an oven (Cole-Parmer StableTemp oven, Sydney, Australia). The slides were incubated overnight at $4^{\circ} \mathrm{C}$ with the following primary antibodies: mouse monoclonal anti-rat granulocyte (HIS48, 1:50; BD Pharmingen, San Diego, CA, USA) to identify neutrophils; mouse monoclonal antiCD68 (ED1) (1:500; Abcam, Cambridge, MA, USA) to identify macrophages; rabbit polyclonal anti-human VEGF A-20 (sc-152, 1:500; Santa Cruz Biotechnology, Santa Cruz, CA, USA) as a proangiogenic factor; rabbit monoclonal anti-CD34 (EP373Y, 1:500; Abcam) and rabbit polyclonal anti-human von Willebrand Factor (vWF) (ready-to-use; Dako, Carpinteria, CA, USA) to identify endothelial cells associated with capillaries ( $\mathrm{Qu}$ et al., 1997; Niiyama et al., 2003; Fujino et al., 2005; Wiik et al., 2005; Ho et al., 2006; Hollemann et al., 2008); and mouse monoclonal anti-nestin (Rat-401, 1:400; Santa Cruz Biotechnology) as a marker of maturing endothelial cells in muscle (Cizkova et al., 2009b). The slides were then incubated for $40 \mathrm{~min}$ with a goat anti-mouse and anti-rabbit secondary antibody conjugated with horseradish peroxidase (Dako). Color was developed using 3,3'-diaminobenzidine (DAB Substrate Kit; Dako) followed by counter stain with Mayer's hematoxylin. The exclusion of the primary antibody as well an isotype control (mouse IgM isotype control; BD Pharmingen) served as negative controls.

\section{Image Analysis}

Slides were scanned using a Leica SCN400 slide scanner (Leica Microsystems, Wetzlar, Germany), and images were captured using Digital Image Hub software (Leica Microsystems). Briefly, at $\times 40$ magnification, 10 fields of view were captured and quantified per slide for all six animals per treatment group 
and time point. ImageJ software was used to quantify areas of positive stain and to identify cells and tissue of interest. To quantify neutrophils and macrophages, positively stained cells were counted and are expressed as the number of cells per field of view. The 10 fields of view were averaged, and a single value was recorded per animal. The expression of CD34, vWF, VEGF, and nestin was assessed by the area of positive stain as a percentage of the total area of tissue within the field of view. Using this relative approach avoided problems caused by swelling of muscle fibers and endothelial cells, and allowed us to compare samples more reliably. Areas of muscle tissue with vessels with a diameter $>100$ $\mu \mathrm{m}$ and longitudinally oriented myofibers were excluded.

Cross-sectional area of muscle fibers was assessed by tracing the outline of 100 fibers using Digital Image Hub software to calculate the fiber area. Regenerating fibers were identified as those fibers with centrally located nuclei and are expressed as a proportion of the total number of fibers in 10 fields of view. Experimental and control groups were compared, and the numbers of inflammatory cells and extent of angiogenesis were graphically represented to determine effects of the ice treatment.

Capillary density was quantified by counting the number of CD $34^{+}$cells and fibers from five fields of view per slide at $\times 20$ magnification using Digital Image Hub software. Capillary density is expressed as capillaries per fiber and capillaries per millimeters squared. As reported by Ochoa et al. (2007), necrosis in the tissue sections obtained at 1,3, and $7 \mathrm{~d}$ after injury made it difficult to identify the borders of individual muscle fibers at these points. Accordingly, we could quantify capillary density only at $28 \mathrm{~d}$ after injury.

\section{Analysis of Vessel Volume}

Quantitative, three-dimensional characterization of vessel volume in muscle tissue was performed using microcomputed tomography (micro-CT). This analysis was conducted on a separate group of 36 rats from those rats used for muscle histology and immunohistochemistry (see Figure 1).

Immediately after euthanasia, the vasculature was flushed with heparinized saline ( $0.9 \%$ normal saline and heparin sodium (100 $\mathrm{U} / \mathrm{ml}$ ), Pfizer Ltd, Sydney, Australia) using a peristaltic infusion pump (Pump 1: Cole-Parmer, 6-600 RPM, Extech Equipment Pty Ltd, Melbourne, Australia). Once the perfusate returned clear at the exit point at the right atrium, the blood vessels were then perfused with Microfil contrast agent (MV-122 Microfil kit, consisting of MV-compound, MV-diluent, and MV-curing agent; Flow Tech Inc., Carver, MA, USA), as described by Duvall et al. (2004), using a second peristaltic pump (Pump 2: $505 \mathrm{U}$, 220 RPM, Watson Marlow Ltd, NSW, Australia). The volume of contrast agent used per rat was $165 \mathrm{ml}$ and comprised a compound-diluent ratio of 1:2 mixed with $10 \%$ curing agent (i.e., $50 \mathrm{ml}$ compound, $100 \mathrm{ml}$ diluent, and $15 \mathrm{ml}$ curing agent). The contrast agent was pumped into the rat at a rate of 20 $\mathrm{ml} / \mathrm{min}$ to keep the perfusion pressure low enough to prevent any vasculature breakage or leakage. Not all of the contrast agent remained within the vasculature because the right atrium was punctured to release the perfusion media after perfusion of the vasculature. However, the perfused volume and duration of perfusion ensured complete perfusion of the animal. This technique does not measure edema. Rather, because the contrast agent was limited to vessel space, no leakage of the contrast agent into extravascular space was observed by micro-CT or histological evaluation.

After perfusion, the rats were stored at $4{ }^{\circ} \mathrm{C}$ overnight to allow the contrast agent to polymerize. The next day, the hind limbs were removed, and a tissue biopsy was taken from the region of interest (as described above) using an 8-mm disposable biopsy punch. This approach ensured that biopsies were obtained consistently from the same region of the muscle in each animal. The muscle biopsies were scanned using a micro-CT imaging system ( $\mu$ CT 40, Scanco Medical, Bassersdorf, Switzerland) and evaluated using Scanco software ( $\mu$ CT Evaluation Program, V6.5-3, Scanco Medical). The muscle biopsies were scanned at an energy of $55 \mathrm{kVp}$, intensity of $145 \mu \mathrm{A}$, and integration time of $250 \mathrm{~ms}$, which resulted in a voxel size of $6 \mu \mathrm{m}$. The vascular network was segmented from the surrounding tissue using a lower threshold of 1,434 Hounsfield units and a low-pass Gaussian filter $(\sigma=0.8$, support $=1)$. The total volume of the smaller blood vessels ( $<78 \mu \mathrm{m}$ diameter) was quantified for the top 250 image slices of the biopsy scans. These data were used to calculate vessel volume. To reduce the potential variability within the micro-CT results, data from the injured rats was normalized relative to the uninjured rats (i.e., injured/uninjured $\times 100)$. Outliers in the vessel volume data were identified using the formula mean $-(1.5 \times \mathrm{SD})<$ measured value $<$ mean + $(1.5 \times \mathrm{SD})$. Figure 2 shows a representative micro-CT image of the vascular network within a biopsy stack (250 slices) from one animal $1 \mathrm{~d}$ after injury. Figure 3 shows a histogram representing the distribution of vessels with diameter 6-78 $\mu \mathrm{m}$ within a biopsy stack (250 slices) from one animal $1 \mathrm{~d}$ after injury.

\section{Statistical Analysis}

All data were tested and confirmed as normally distributed using the Shapiro-Wilks formula. Two-factor analysis of variance was

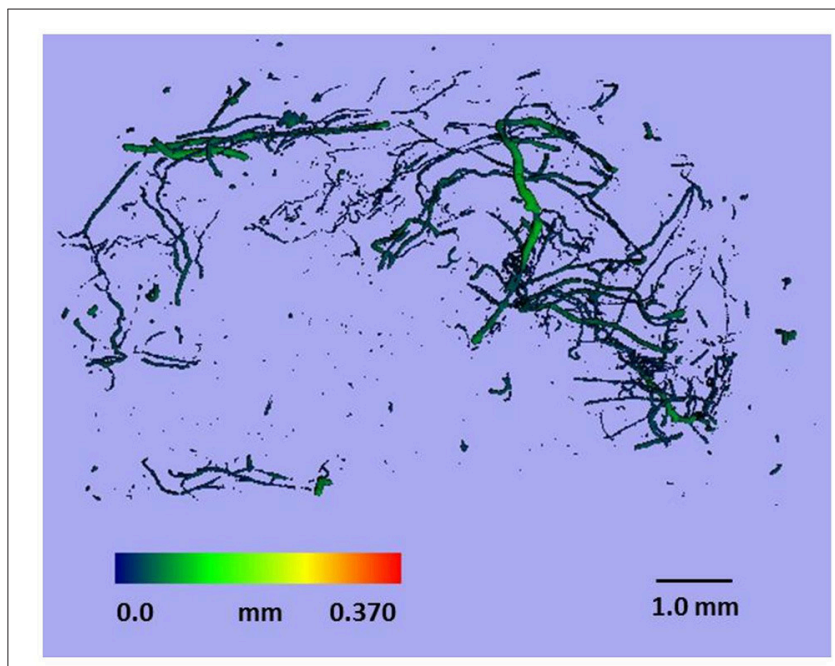

FIGURE 2 | Representative micro-CT image of the vascular network within a biopsy stack (250 slices) from one animal $1 \mathrm{~d}$ after injury. 


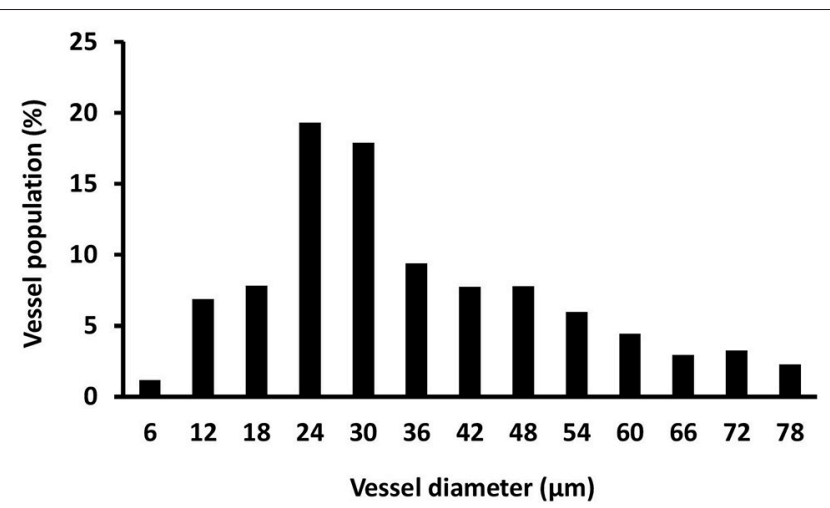

FIGURE 3 | Histogram showing the distribution of vessel size. Vessel size was determined by micro-CT (vessel diameter 6-78 $\mu \mathrm{m}$ ) within a biopsy stack (250 slices) from one animal $1 \mathrm{~d}$ after injury.

performed to determine if there were any main effects of time and group or group $\times$ time interactions. If any significant $(P<0.05)$ main effects were evident, unpaired $t$-tests were used to compare the control group vs. the icing and sham groups, and the icing vs. sham groups. This statistical analysis was performed using IBM SPSS Statistics (version 23, IBM, Armonk, NY, USA). The false discovery rate was used to control for multiple comparisons between groups. Cohen's effect size $(d)$ was also calculated to assess treatment effects and was considered small $(d<0.2)$, moderate $(d=0.2-0.5)$, or large $(d \geq 0.8)$. All data are presented as mean $\pm \mathrm{SD}$.

\section{RESULTS}

Routine histology with H\&E staining revealed extensive necrosis of muscle fibers $1 \mathrm{~d}$ after injury in both the sham and icing groups (Figure 4). The necrotic muscle fibers were identified by enlarged myofibers without nuclei. Inflammatory cell infiltration accompanied the necrosis and comprised mainly multinucleated leukocytes (neutrophils) (Figure 5). In the rats sacrificed at $3 \mathrm{~d}$ after injury, the necrosis had cleared almost entirely in the sham group, whereas several necrotic areas were still present within the icing group. The inflammatory infiltrate at this time consisted mainly of mononuclear leukocytes, which were identified as macrophages by their size and single nuclei (Figure 6). Several macrophages were visible throughout the necrotic tissue in the sham group, but these cells were not as prominent in the icing group. In the rats sacrificed at $7 \mathrm{~d}$ after injury, the necrosis had cleared, and several immature centrally nucleated muscle fibers were evident in muscle tissue from both the sham and icing groups. In the rats sacrificed at $28 \mathrm{~d}$ after injury, the inflammatory cell influx had resolved, and normal tissue structure was almost restored with the exception of large maturing myofibers.

The numbers of neutrophils were greater in muscle from the icing and sham groups compared with the control group at $1 \mathrm{~d}$ and $3 \mathrm{~d}$ after injury (Figure 7A). Neutrophils were more abundant in muscle from the sham group than in the icing group at $1 \mathrm{~d}$ after injury $(d=1.9 ; P=0.010)$, whereas neutrophils were more abundant in muscle from the icing group than in the sham group at $3 \mathrm{~d}$ after injury $(d=1.6 ; P=0.027)$. There were no neutrophils present in muscle in either group at 7 and $28 \mathrm{~d}$ after injury (data not shown).

The number of macrophages was greater in muscle from the icing and sham groups compared with the control group at all time points after injury (Figure 7B). Macrophages were more abundant in muscle from the sham group than in the icing group at $1 \mathrm{~d}(d=2.0 ; P=0.035)$ and $3 \mathrm{~d}$ after injury $(d=2.5 ; P=$ 0.001 ). By contrast, macrophages were more abundant in muscle from the icing group than in the sham group at $7 \mathrm{~d}(d=1.5 ; P=$ $0.045)$ and $28 \mathrm{~d}(d=1.9 ; P=0.020)$ after injury.

CD34 staining was used to identify endothelial cells (Wiik et al., 2005; Ho et al., 2006; Hollemann et al., 2008) (Figure 8). Staining for CD34 was quantified as the area of positive staining as a percentage of the total area of tissue within the field of view. The percentage of CD34-stained area was lower in muscle from the icing and sham groups than in the control group at $1 \mathrm{~d}$ after injury $(P<0.001)$ (Figure 9A). Thereafter, the percentage of CD34-stained area was greater in muscle from the icing and sham groups than in the control group. The percentage of CD34stained area tended to be greater in muscle from the sham group than in the icing group at $3 \mathrm{~d}(d=1.1 ; P=0.082)$ and $7 \mathrm{~d}(d=$ $1.3 ; P=0.053$ ) after injury. Conversely, the percentage of CD34stained area was greater in muscle from the icing group than in the sham group at $28 \mathrm{~d}$ after injury $(d=1.7 ; P=0.013)$.

vWF staining was used to identify endothelial cells ( $\mathrm{Qu}$ et al., 1997; Fujino et al., 2005; Hollemann et al., 2008). In contrast to the staining for CD34 and consistent with other reports (Qu et al., 1997), vWF staining was restricted to larger, well-established mature vessels (Figure 10). Staining for vWF was quantified as the area of positive staining as a percentage of the total area of tissue within the field of view. The percentage of vWF-stained area was greater in muscle from the icing and sham groups than in the control group at all time points after injury (Figure 9B), and this percentage was greater in muscle from the sham group than in the icing group at $3 \mathrm{~d}(d=1.6 ; P=0.022)$ and $7 \mathrm{~d}(d=3.0$; $P<0.001)$ after injury.

Broad background staining for VEGF was apparent in muscle tissue, and foci of VEGF staining were evident around blood vessels (Figure 11). The percentage of VEGF-stained area was greater in muscle from the icing and sham groups than in the control group at all time points after injury but appeared to peak at $3 \mathrm{~d}$ after injury (Figure 9C). It was greater in muscle from the sham group vs. the icing group at $3 \mathrm{~d}$ after injury $(d=2.0$; $P=0.007)$.

We used nestin to identify maturing endothelial cells (Cizkova et al., 2009b). Similar to vWF staining, nestin staining was localized to larger blood vessels (Figure 12). Staining for nestin was quantified as the area of positive stain as a percentage of the total area of tissue within the field of view. The area of nestin staining was greater in muscle from the icing and sham groups than in the control group at all time points after injury (Figure 9D). The area of nestin staining was greater in muscle from the sham group than in the icing group at $3 \mathrm{~d}$ after injury $(d=3.2 ; P<0.001)$ but was greater in muscle from the icing group than in the sham group at $7 \mathrm{~d}(d=2.7 ; P=$ 


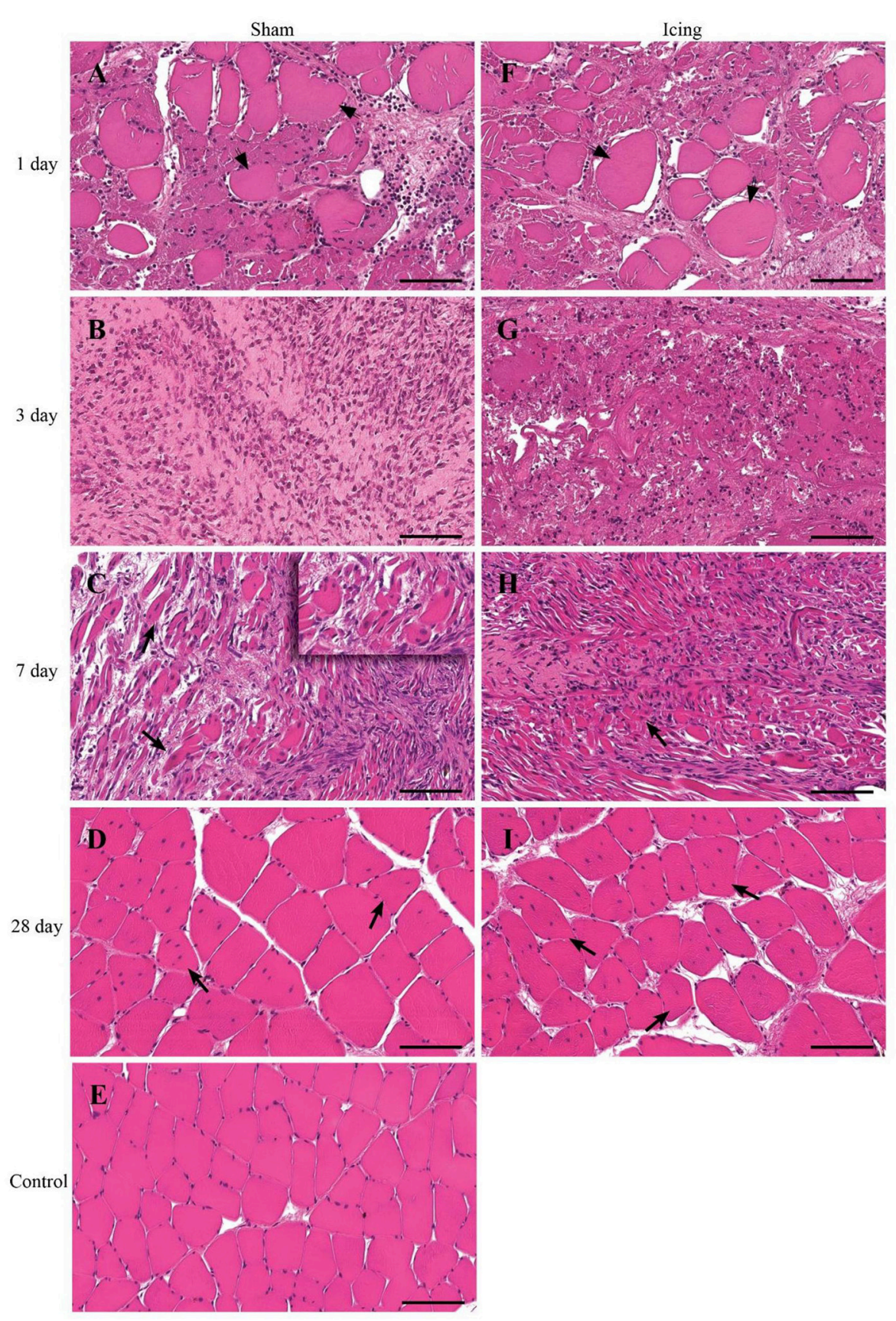

FIGURE 4 | Representative cross sections of skeletal muscle tissue. Muscle tissue was stained with H\&E in the sham group (A-D) and the icing group (F-I) at $1,3,7$, and $28 \mathrm{~d}$ after injury. (E) Shows muscle tissue from an uninjured rat for comparison. Arrowheads indicate necrotic muscle fibers. Arrows indicate regenerating muscle fibers (centrally placed nuclei). Scale bar $=100 \mu \mathrm{m}$.

$0.001)$ after injury. Nestin was also detected in the sarcoplasm of immature myotubes and myofibers. At $28 \mathrm{~d}$, few large muscle fibers expressed nestin.

The vessel volume in muscle was determined by micro-CT. The vessel volume was greater in the sham group than in the icing group at $3 \mathrm{~d}(d=2.5 ; P=0.029)$ and $7 \mathrm{~d}(d=3.2 ; P=0.021)$ after injury, whereas there was no difference between the groups after $28 \mathrm{~d}(P=0.84)$ (Figure 13A). The number of capillaries per fiber at $28 \mathrm{~d}$ after injury did not differ significantly $(P=$ $0.59)$ between the icing group $(1.90 \pm 0.27)$ and the sham group $(1.82 \pm 0.18)$. The number of capillaries per millimeter squared also did not differ significantly $(P=0.13)$ between the icing group $(240 \pm 24)$ and the sham group $(218 \pm 0.23)$ at $28 \mathrm{~d}$ after injury.

At $7 \mathrm{~d}$ after injury, many centrally nucleated regenerating muscle fibers were present in the sham group, whereas only 


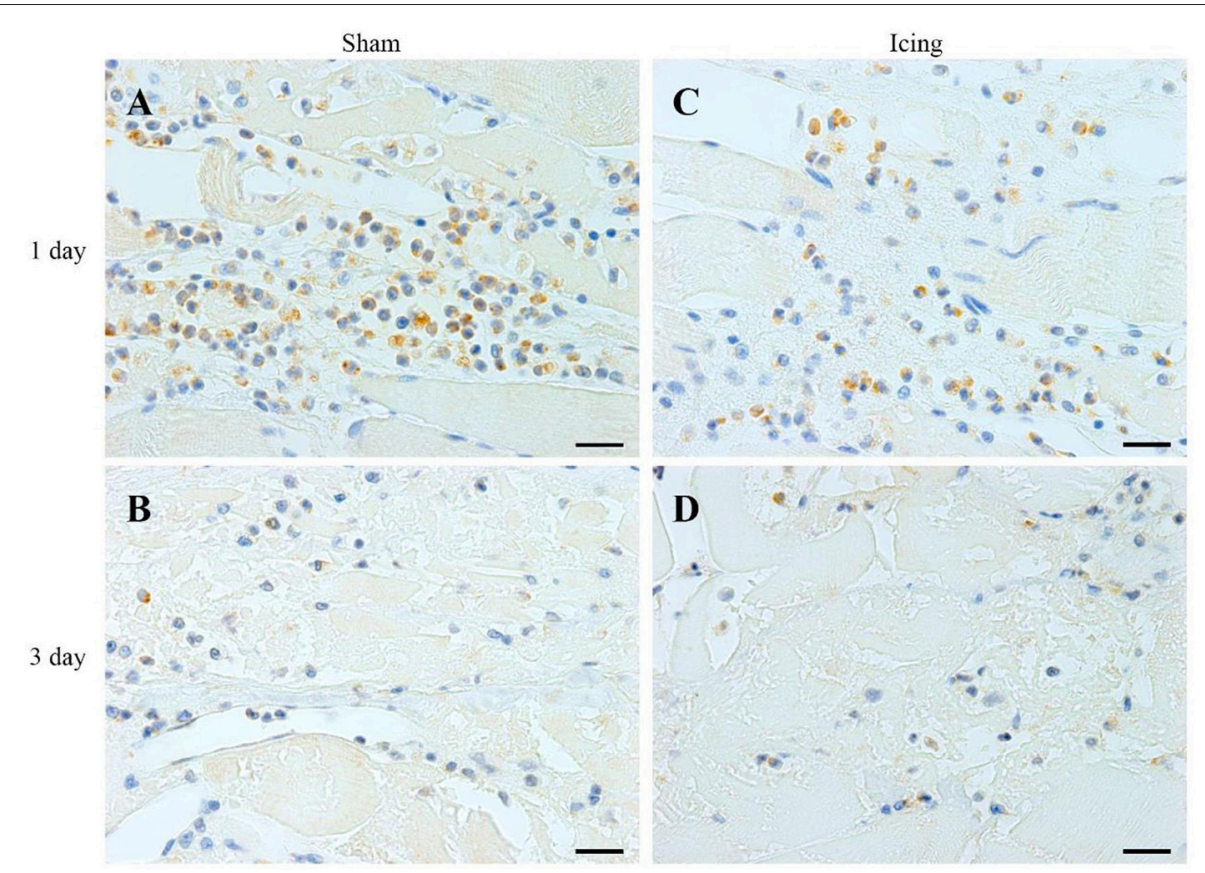

FIGURE 5 | Representative images of immunohistochemistry staining of neutrophils. Skeletal muscle tissue was stained with HIS48 antibody to identify neutrophils. Sham (A,C) and icing (B,D) groups at 1 and $3 \mathrm{~d}$ after injury. Scale bar $=20 \mu \mathrm{m}$.

a few were present within the icing group. The percentage of regenerating fibers relative to the total number of fibers did not differ significantly between the icing and sham groups at $7 \mathrm{~d}$ after injury $(P=0.11)$. By contrast, this percentage was greater in the icing group than in the sham group at $28 \mathrm{~d}$ after injury $(d=1.5$; $P=0.026$ ) (Figure 13B). There were no significant differences between the icing and sham groups for fiber cross-sectional area at $7 \mathrm{~d}(P=0.35)$ or $28 \mathrm{~d}(P=0.30)$ (data not shown).

\section{DISCUSSION}

The aim of this study was to examine the effects of icing soon after muscle contusion injury on subsequent inflammation, angiogenesis, revascularization, and myofiber regeneration. Our study is the first to demonstrate that icing delayed and/or attenuated the expression of proangiogenic factors and changes in vessel volume in regenerating muscle in the first $7 \mathrm{~d}$ after injury. Despite these differences, capillary density and the crosssectional area of myofibers did not differ significantly between the icing and sham groups. These findings suggest that, although icing may mildly suppress inflammation and some aspects of angiogenesis/revascularization, these effects are not sufficient to retard muscle regeneration after contusion injury.

Contusion injury caused extensive necrosis in skeletal muscle during the first $3 \mathrm{~d}$ after injury. Icing appeared to prolong the clearance of necrotic tissue, possibly by preventing (or delaying) the infiltration of neutrophils and macrophages into the damaged muscle (Teixeira et al., 2003; Summan et al., 2006). The decline or delay in infiltration of inflammatory cells is consistent with the results of other studies that have treated muscle injuries with ice (Carvalho et al., 2010; Puntel et al., 2011; Takagi et al., 2011) or cold saline (Lee et al., 2005; Schaser et al., 2006, 2007). This decline/delay in inflammation may result from a decrease in the expression of adhesion molecules on the surface of inflammatory cells (Haddix et al., 1996; Inamasu et al., 2001).

This is the first study to investigate whether icing influences angiogenesis and vessel volume in regenerating muscle. We stained muscle tissue for CD34 and vWF to identify capillaries (Qu et al., 1997; Niiyama et al., 2003; Fujino et al., 2005; Wiik et al., 2005; Ho et al., 2006; Hollemann et al., 2008). Contusion injury induced a sustained increase in the expression of vWF in muscle that lasted at least $28 \mathrm{~d}$. Conversely, contusion injury appeared to suppress CD34 expression in muscle in the first 7 $\mathrm{d}$ after injury. Icing reduced the expression of vWF and CD34 (to a lesser extent) between 3 and $7 \mathrm{~d}$ after injury. As reported by Ochoa et al. (2007), necrosis in the muscle tissue at 3 and $7 \mathrm{~d}$ after injury made it difficult to identify the border of muscle fibers and therefore to quantify the number of capillaries per fiber (i.e., capillary density). Nevertheless, we were able to quantify the area of positive staining for CD34, vWF, and VEGF as percentages of the total area of tissue within the field of view. Despite a difference in CD34 staining intensity in muscle after $28 \mathrm{~d}$ (Figure 9A), capillary density did not differ significantly between the icing and sham groups at this time point. However, it is possible that capillary density differed between these groups at 3 and $7 \mathrm{~d}$ after injury. Some VEGF staining was evident in endothelial cells and surrounding blood vessels (Figure 11), but there was also general background staining for VEGF, which most likely represents staining of muscle cells. As such, we cannot attribute the VEGF staining exclusively to angiogenesis. 


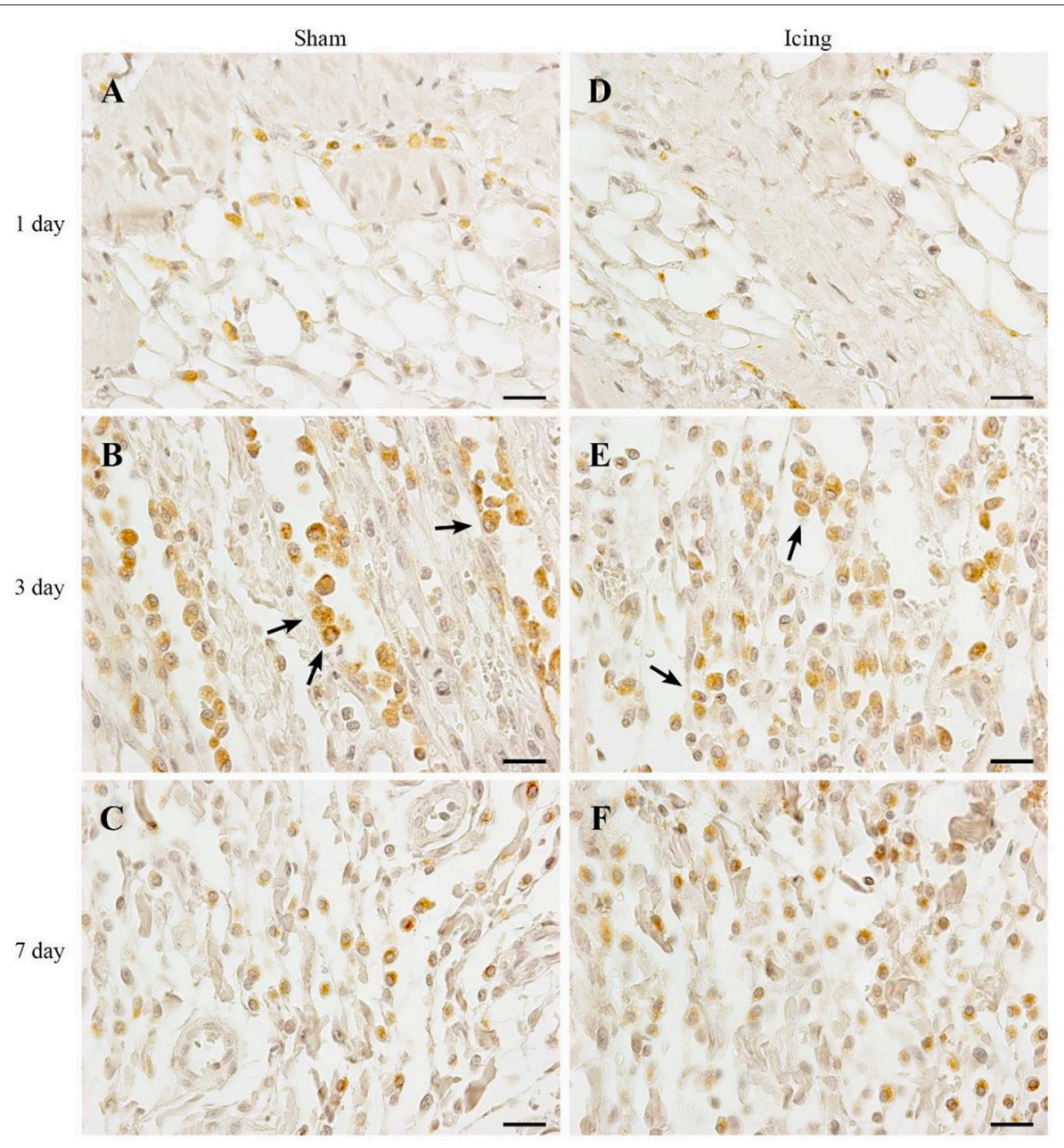

FIGURE 6 | Representative images of immunohistochemistry staining of macrophages. Skeletal muscle tissue was stained with CD68 antibody to identify macrophages. Sham (A-C) and icing (D-F) groups at 1, 3, and $7 \mathrm{~d}$ after injury. Arrows indicate macrophages. Scale bar $=20 \mu \mathrm{m}$.
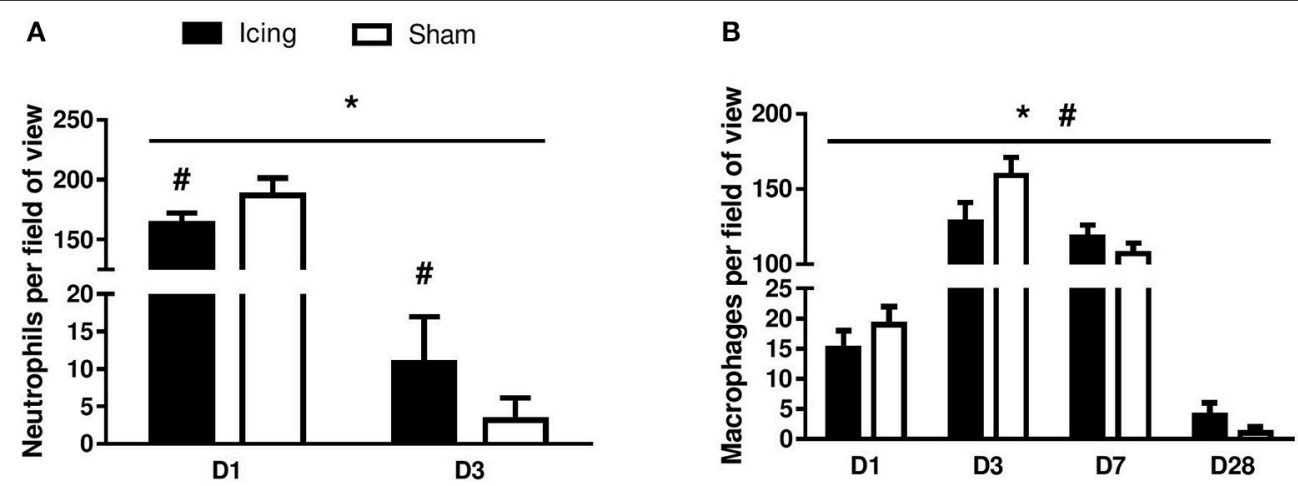

FIGURE 7 | Quantitative data for neutrophil (A) and macrophage (B) count in skeletal muscle tissue. $n=6$ rats per group. Data are mean \pm SD and are expressed as a fold-difference from uninjured control rats. Neutrophils and macrophages were not present in skeletal muscle tissue from uninjured control rats. Main effects for neutrophil counts: time $(P<0.001)$, group $(P=0.029)$, and group $\times$ time interaction $(P<0.001)$. Main effects for macrophage counts: time $(P<0.001)$, group $(P=$ 0.008), and group $\times$ time interaction $(P<0.001)$. ${ }^{*} P<0.05$ for unpaired $t$-test vs. uninjured control rats. $\# P<0.05$ for unpaired $t$-test vs. sham-treated rats. 

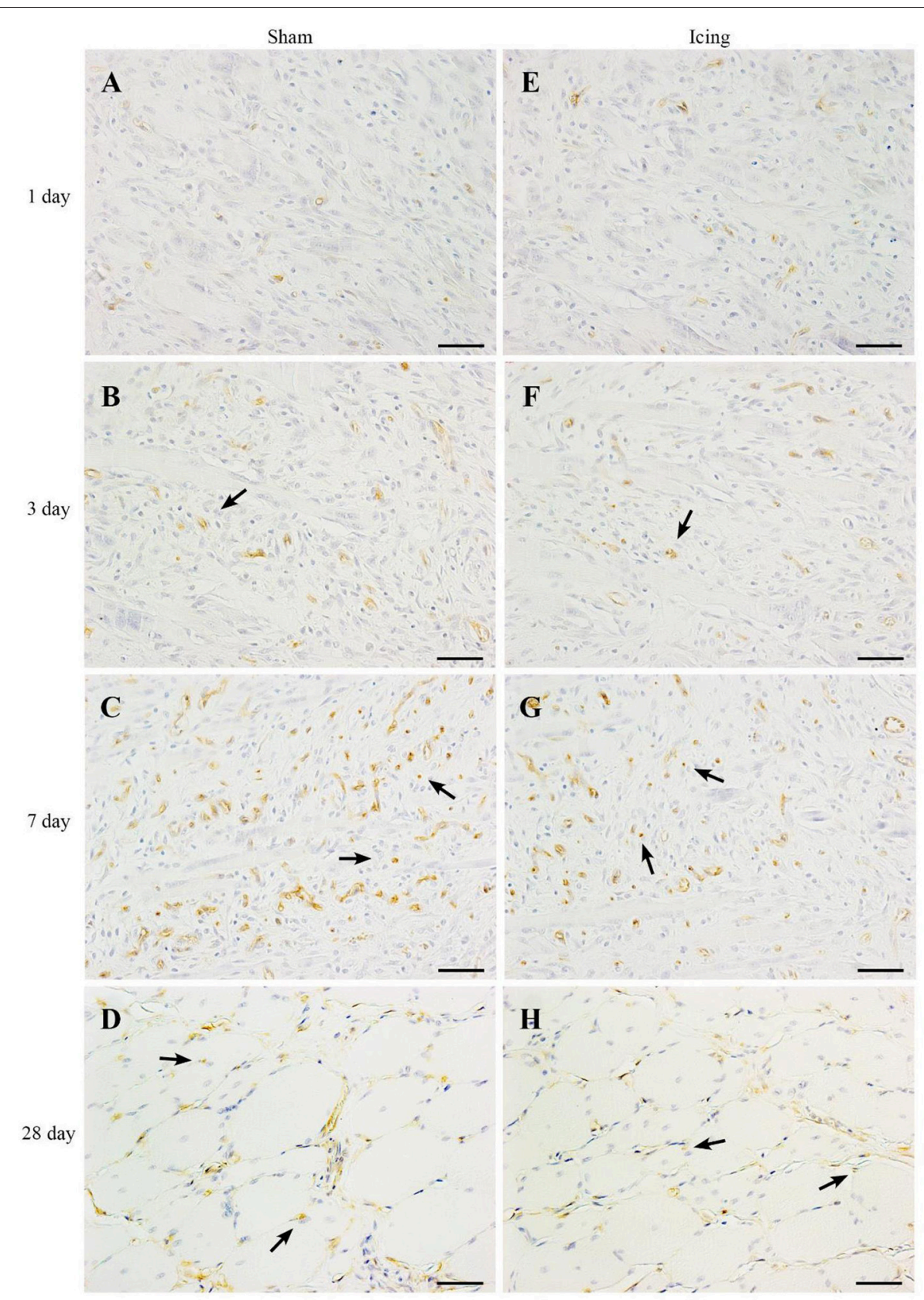

FIGURE 8 | Representative images of immunohistochemistry staining of endothelial cells. Skeletal muscle tissue was stained with CD34 antibody to identify endothelial cells. Sham (A-D) and icing (E-H) groups at 1, 3, 7, and $28 \mathrm{~d}$ after injury. Arrows indicate vessels. Scale bar $=50 \mu \mathrm{m}$.

These differences in staining for vWF and VEGF between the icing and sham groups were accompanied by smaller vessel volume at 3 and $7 \mathrm{~d}$ after injury, as measured by contrastenhanced micro-CT (Figure 13A). Because we could not assess capillary density at these time points, it is difficult to compare the time courses of angiogenesis and collateral vessel growth, as assessed by vessel volume. Others have reported differences in the time course of angiogenesis and collateral vessel growth in skeletal muscle following hind limb ischemia (Ito et al., 1997;
Hershey et al., 2001, 2003). It is possible that icing exerted a greater effect on vessel volume than on angiogenesis. The present findings contrast with previous research showing that perfusion of skeletal muscle with cold saline at $8^{\circ} \mathrm{C}$ restores functional capillary density and venule diameter $1 \mathrm{~d}$ after injury (Schaser et al., 2006, 2007). Our results are not directly comparable with this other research because we assessed static measures of angiogenesis, whereas Schaser et al. measured changes in microcirculatory dynamics in muscle using intravital microscopy 

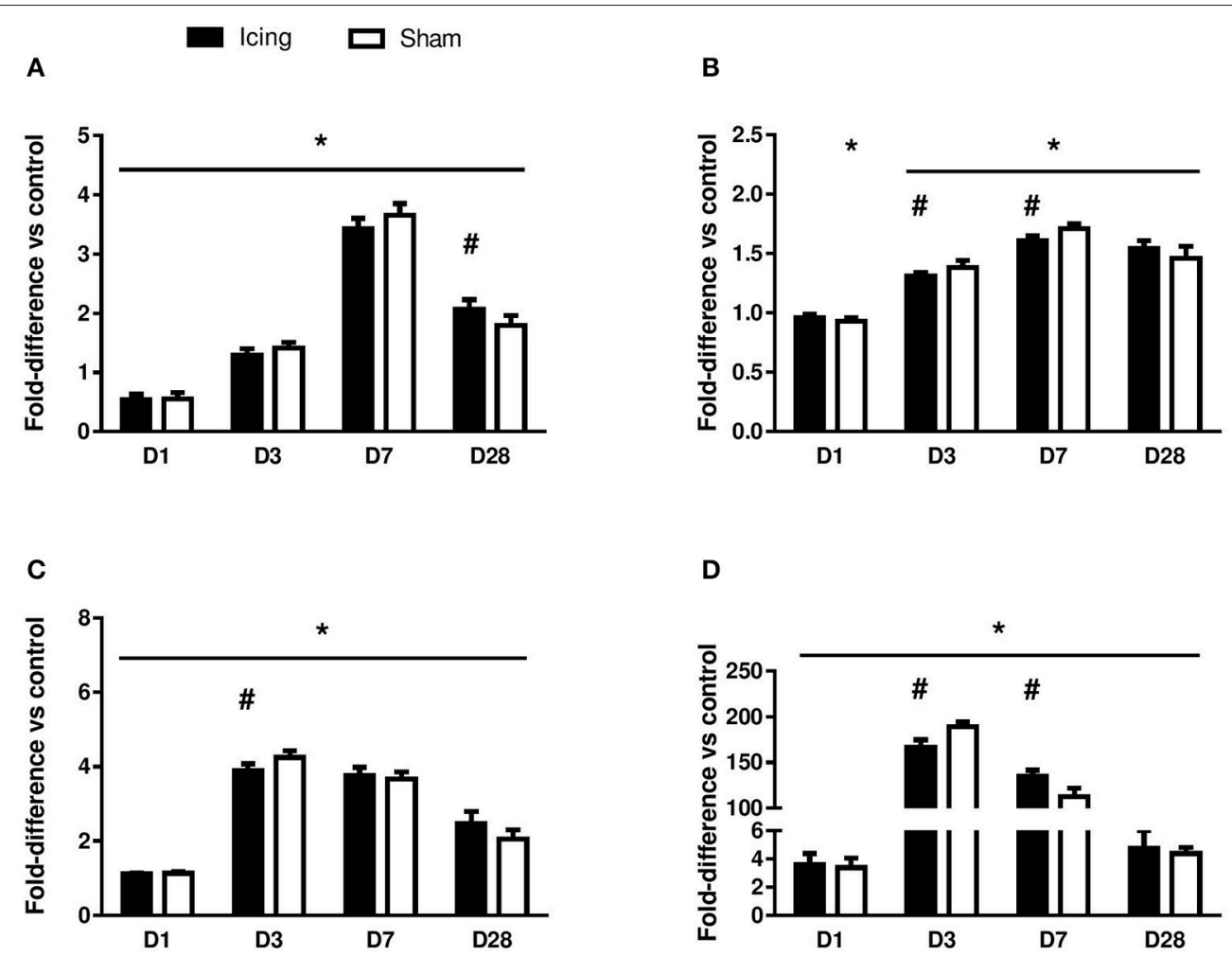

FIGURE 9 | Quantitative data for the area of positive staining for CD34 (A), vWF (B), VEGF (C), and nestin (D). The data are shown as a percentage relative to the total area of muscle tissue within the field of view. Data are mean $\pm \mathrm{SD}, n=6$ rats per group, and are expressed as a fold difference relative to the uninjured control rats. Main effects for CD34: time effect $(P<0.001)$, group effect $(P<0.001)$, and group $\times$ time interaction $(P<0.001)$. Main effects for vWF: time effect $(P<$ 0.001), group effect $(P=0.63)$, and group $\times$ time interaction $(P<0.001)$. Main effects for VEGF: time effect $(P<0.001)$, group effect $(P=0.56)$, and group $\times$ time interaction $(P<0.001)$. Main effects for nestin: time effect $(P<0.001)$, group effect $(P=0.98)$, and group $\times$ time interaction $(P<0.001)$. $P<0.05$ for unpaired $t$-test vs. uninjured control rats. $\# P<0.05$ for unpaired $t$-test vs. sham-treated rats.

(Schaser et al., 2006, 2007). Their assessment was also restricted to $1 \mathrm{~d}$ after injury. Icing may induce different effects on microcirculatory dynamics in muscle in the days and weeks after injury.

Various factors or mechanisms may explain why icing attenuated and/or delayed the expression of VEGF and vWF in regenerating muscle tissue. Icing delays satellite cell proliferation in damaged muscle (Takagi et al., 2011), which may also partly explain why icing reduced the expression of VEGF and vWF in the current study. Evidence for this notion is that proliferating and differentiating satellite cells stimulate human vascular endothelial cells to form tubular-like structures in vitro (Christov et al., 2007), possibly by secreting VEGF and expressing HIF$1 \alpha$ (Rhoads et al., 2009). Skeletal muscle expresses cold shock domain protein A (Saito et al., 2011). This protein suppresses VEGF promoter activity and VEGF secretion by skeletal muscle cells under normoxic and hypoxic conditions (Saito et al., 2011) and suppresses tube formation by endothelial cells (Saito et al., 2011). Although it is unknown whether icing influences the expression of cold shock domain protein A in skeletal muscle, it is possible that this protein may have been partially responsible for reducing/delaying VEGF and vWF expression in the present study.
Incubation of human vascular endothelial cells under "hypothermic" conditions (i.e., $\leq 34^{\circ} \mathrm{C}$ ) reduces their capacity to form tubes in vitro (Coassin et al., 2010; Takeyama et al., 2015). Hypothermia also significantly reduces VEGF secretion and mRNA expression by retinal pigment epithelial cells (Coassin et al., 2010; Takeyama et al., 2015). These effects appear to be linked to lower cellular metabolism (Coassin et al., 2010; Takeyama et al., 2015). When amputated, ischemic limbs of cats are exposed to hypothermia, ATP and phosphocreatine depletion and tissue acidosis are attenuated (Osterman et al., 1984; Sapega et al., 1988).

The effects of hypothermia on the production of reactive oxygen species (ROS) are variable (Rauen and de Groot, 2002; Alva et al., 2013b). Some research demonstrates that when applied in isolation, hypothermia increases the production of ROS by adenocarcinomic alveolar basal epithelial (A549) cells (Sun et al., 2016) and induces lipid peroxidation and decreases the blood concentration of glutathione in rats (Dede et al., 2002). Conversely, many studies have reported that when applied following injury, hypothermia reduces the formation of ROS in neuronal cells (Gao et al., 2014, 2016), PC12 adrenal cells (Hasegawa et al., 2009), brain tissue (Maier et al., 2002; Horiguchi et al., 2003; Lv et al., 2016) liver tissue and blood (Alva 


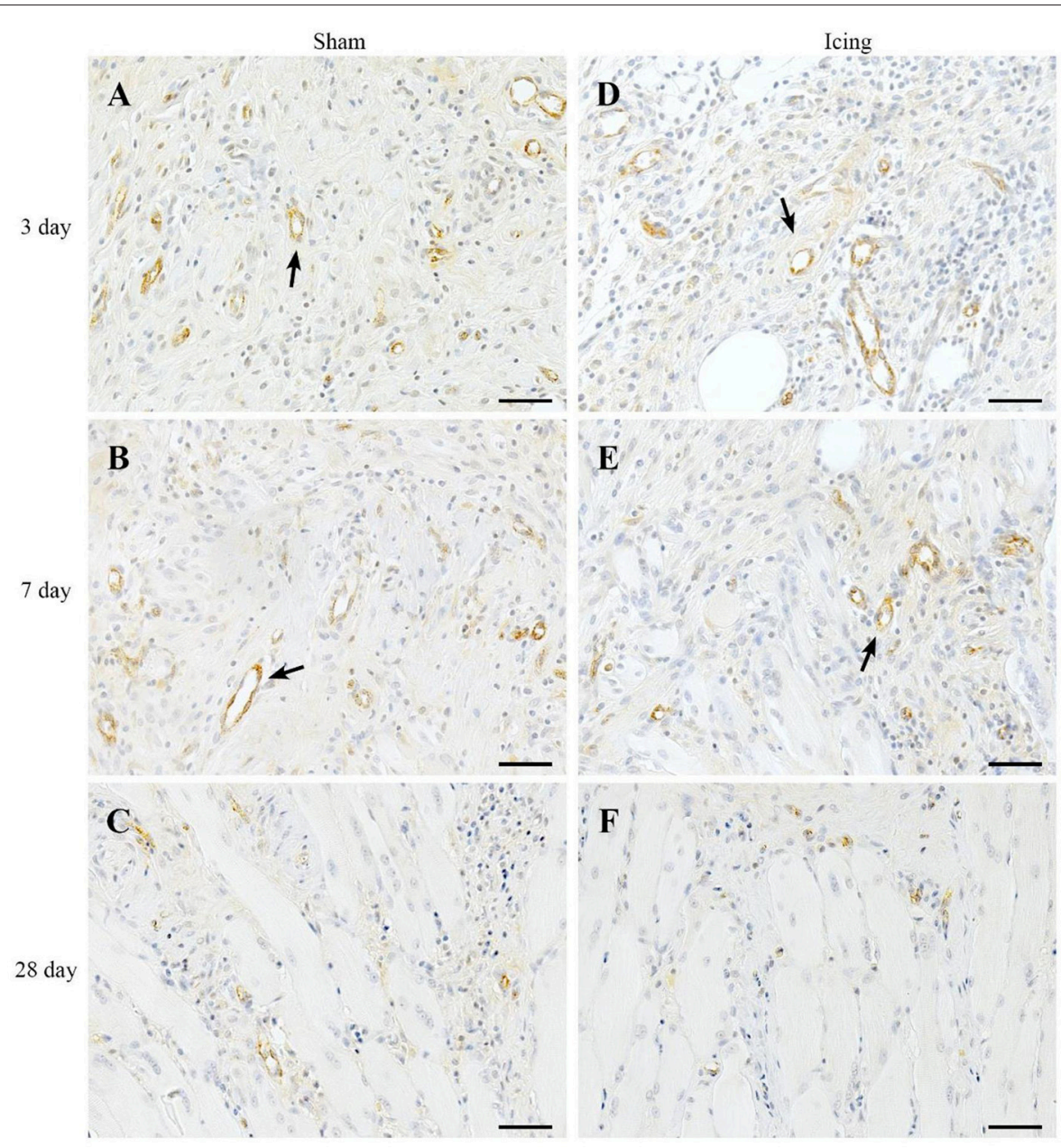

FIGURE 10 | Representative images of immunohistochemistry staining for vWF antibody to identify endothelial cells in muscle tissue. Sham (A-C) and icing (D-F) groups at 1, 3, 7, and $28 \mathrm{~d}$ after injury. Arrows indicate mature vessels. Scale bar $=50 \mu \mathrm{m}$.

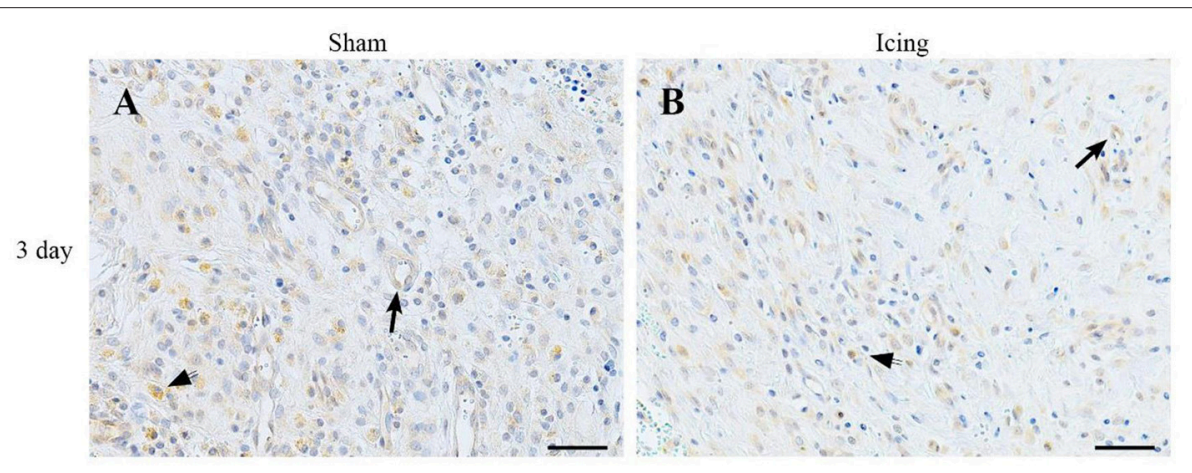

FIGURE 11 | Representative images of immunohistochemistry staining with VEGF antibody. Muscle tissue was obtained from the sham (A) and icing (B) groups at $3 \mathrm{~d}$ after injury. Arrows indicate vessels expressing VEGF. Arrowheads indicate positively stained macrophages. Scale bar $=50 \mu \mathrm{m}$.

et al., 2013a). In injured rat skeletal muscle, icing decreases the formation of superoxide anions, lipid peroxidation, and activity of the antioxidant enzyme catalase (Merrick et al., 1999; Carvalho et al., 2010). These findings contrast with other evidence that hypoxia stimulates ROS production in skeletal muscle fibers (Zuo and Clanton, 2005; Zuo et al., 2013b). The effects of hypothermia or cryotherapy on ROS production by cells and tissues may therefore depend on various factors 


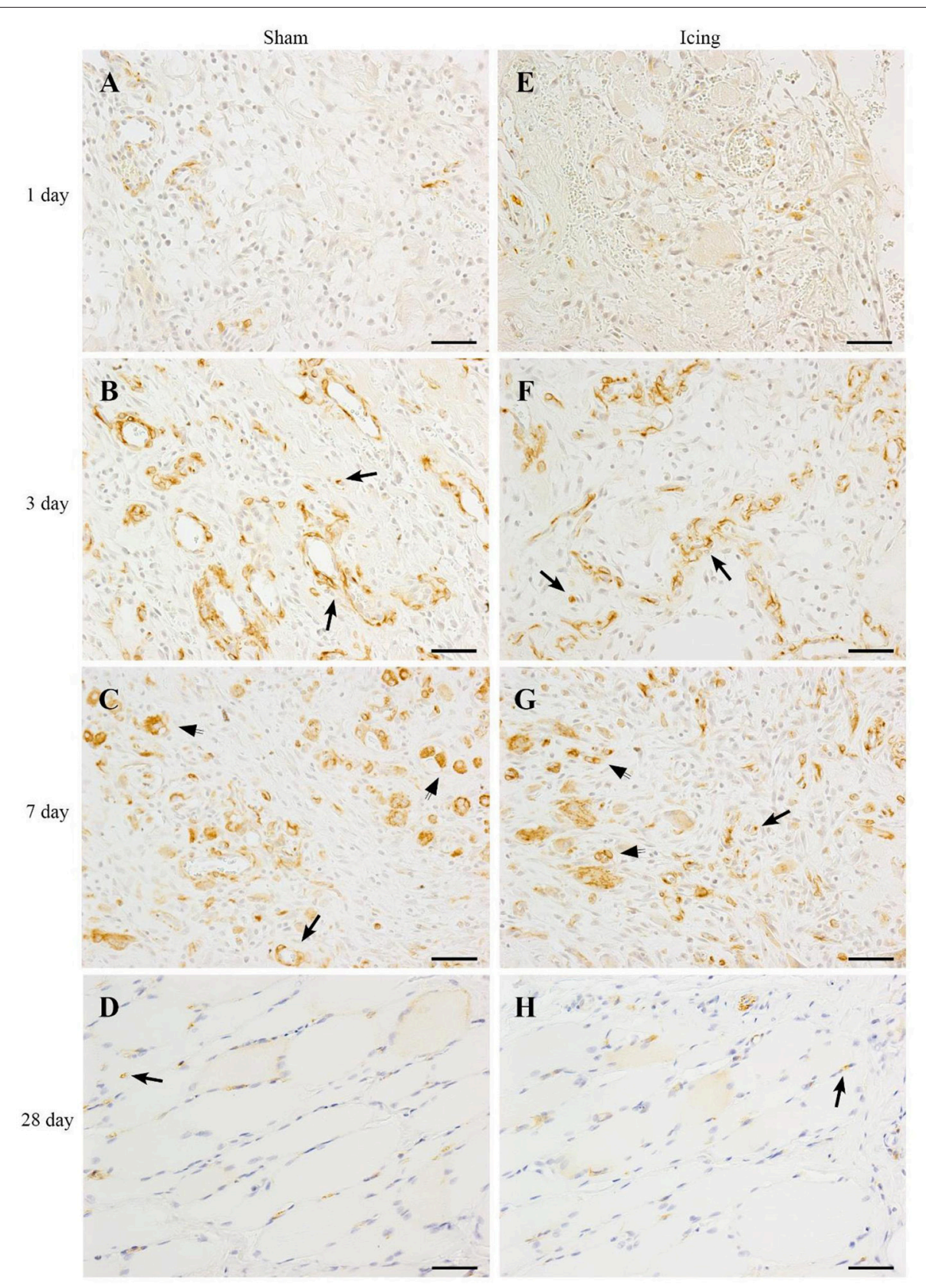

FIGURE 12 | Representative images of immunohistochemistry staining. Nestin antibody was used to identify endothelial cells in muscle tissue from the sham (A-D) and icing (E-H) groups at 1, 3, 7, and $28 \mathrm{~d}$ after injury. Arrows indicate positively stained endothelial cells. Scale bar $=50 \mu \mathrm{m}$.

including the temperature at which cells and tissues are treated, the extent of ischemia and hypoxia that occurs in response to hypothermia or cryotherapy, and whether these treatments are applied to cells/tissues in isolation or after injury (Alva et al., 2013b; Zuo et al., 2013a). We did not measure ROS formation in muscle in the present study, but it is tempting to speculate that icing may have reduced the expression of VEGF and vWF and vessel volume in skeletal muscle by reducing ROS production (Merrick et al., 1999; Carvalho et al., 2010). However, other evidence indicates that hypothermia suppresses the expression of VEGF (and HIF-1 $\alpha$ ) by T98G cells (derived from human glioblastoma multiform) independently of changes in $\mathrm{O}_{2}$ consumption (Tanaka et al., 2010). Evidence also exists that hypothermia increases angiogenesis in the spinal cord (Kao et al., 2011) and brain (Kuo et al., 2010). More research is therefore needed to understand the effects of icing on ROS production and angiogenesis in skeletal muscle following injury.

We measured the expression of nestin as a marker of revascularization in skeletal muscle (Cizkova et al., 2009b). 

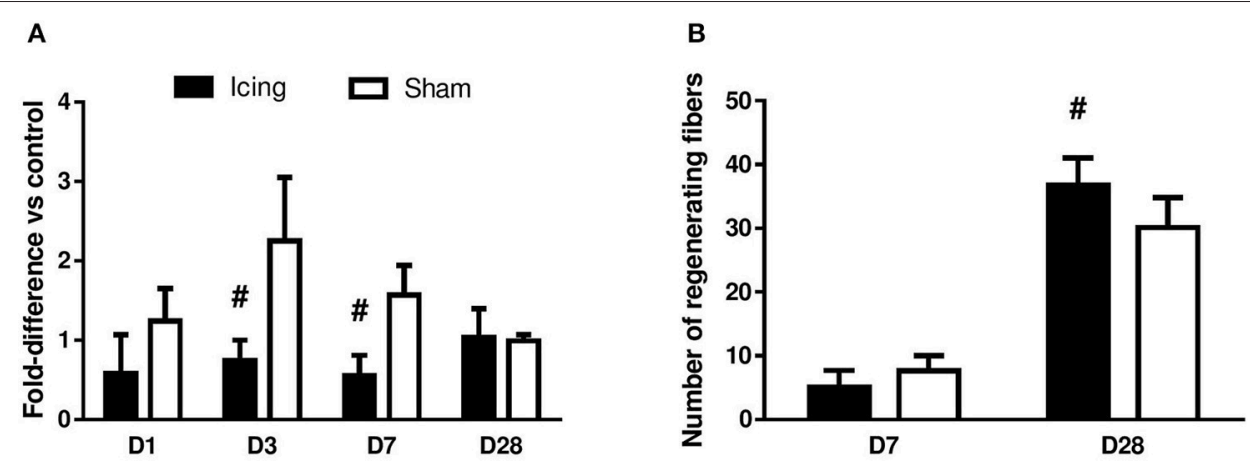

FIGURE 13 | Quantitative data for vessel volume (A) and number of regenerating myofibers (B) in skeletal muscle tissue. Data are mean \pm SD. Data for vessel volume were obtained from $n=4$ rats per group and are expressed as a fold difference relative to the uninjured control rats. Data for number of regenerating myofibers were obtained from $n=6$ rats per group. Main effects for vessel volume: time effect $(P=0.098)$, group effect $(P<0.001)$, and group $\times$ time interaction $(P$ $<0.001)$. $\# P<0.05$ for unpaired $t$-test vs. sham-treated rats.

Nestin has been detected in endothelial cells (Mokry et al., 2004; Cizkova et al., 2009b), pericytes (Birbrair et al., 2014), and blood vessels (Amoh et al., 2005) within skeletal muscle. Consistent with other research (Vaittinen et al., 2001; Cizkova et al., 2009a,b), we observed that nestin expression was greatest in regenerating muscle tissue between 3 and $7 \mathrm{~d}$ after injury. At $3 \mathrm{~d}$ after injury, there appeared to be strong nestin staining around blood vessels (Figure 12), suggesting that nestin was expressed by maturing endothelial cells (Cizkova et al., 2009b). Pericytes also express nestin, colocalize with endothelial cells and capillaries in skeletal muscle, and contribute to angiogenesis (Birbrair et al., 2014). We found that icing attenuated or delayed upregulation of nestin expression in regenerating muscle. Considering that nestin is involved in the differentiation of endothelial cells (Cizkova et al., 2009b), suppression of nestin expression following icing may also have contributed to the reduction in vWF expression and vessel volume that we observed. We did not double-stain the muscle tissue for nestin and another marker of endothelial cells (e.g., CD34, vWF) or pericytes (e.g., NG2). Nor did we stain the muscle for myotubes, Schwann cells, or axons, which also express nestin (Cizkova et al., 2009b). Accordingly, we cannot establish definitively whether the nestin staining that we observed solely represents revascularization.

We found that icing did not alter myofiber cross-sectional area at 7 or $28 \mathrm{~d}$ after injury. However, it did appear to delay myofiber maturation, as indicated by a greater number of immature myofibers with centrally located nuclei at $28 \mathrm{~d}$ after injury (Figure 13B). Our findings contrast with those of Takagi et al, who reported that icing resulted in more immature myofibers at $14 \mathrm{~d}$ (but not at $28 \mathrm{~d}$ ) and smaller myofiber cross-sectional area at $28 \mathrm{~d}$ after injury (Takagi et al., 2011). These differences may be explained by the use of younger rats ( 8 weeks old) and induction of injury by crushing the extensor digitorum longus muscle with forceps for $30 \mathrm{~s}$ in the study by Takagi et al. Collectively, these factors may have resulted in a different degree of muscle injury and/or rate of muscle repair between studies, which may in turn have influenced the efficacy of the icing treatment.

In conclusion, icing attenuated or delayed the infiltration of inflammatory cells, the expression of proangiogenic factors, and change in vessel volume in muscle following injury. However, these effects were not sufficient to reduce capillary density or prevent effective muscle regeneration. We applied ice treatment at only one time point soon after muscle injury. It is possible that more frequent icing may have produced different effects on inflammation, angiogenesis, and myofiber regeneration. We also used only male rats. Icing may have produced different effects in female rats because of the effects of estrogen on the time course and dynamics of muscle regeneration (Enns and Tiidus, 2010). Future research could systematically examine whether the duration, timing, or frequency of icing treatment influence inflammation, angiogenesis, and muscle tissue regeneration after injury. Also of interest is whether icing influences the expression/activity of antiangiogenic factors such as endostatin and angiostatin or the release of neurogenic inflammatory factors (e.g., bradykinin, nerve growth factor, calcitonin gene-related peptide) that regulate pain responses in muscle following injury.

\section{AUTHOR CONTRIBUTIONS}

DS, ZB, MW, TP, RS, and JP designed the study. DS, ZB, and RS performed the experiments. DS, ZB, RS, and JP analyzed and interpreted the data. DS, ZB, MW, TP, RS, and JP drafted and revised the work. DS, ZB, MW, TP, RS, and JP approved the final version. DS, ZB, MW, TP, RS, and JP agree to be accountable for all aspects of the work in ensuring that questions related to the accuracy or integrity of any part of the work are appropriately investigated and resolved.

\section{FUNDING}

This work was funded by a grant from the Institute of Health and Biomedical Innovation at Queensland University of Technology.

\section{ACKNOWLEDGMENTS}

We thank staff at the Central Analytical Research Facility (Histology), Institute for Future Environments, Queensland University of Technology for their assistance in this work. 


\section{REFERENCES}

Alva, N., Azuara, D., Palomeque, J., and Carbonell, T. (2013a). Deep hypothermia protects against acute hypoxia in vivo in rats: a mechanism related to the attenuation of oxidative stress. Exp. Physiol. 98, 1115-1124. doi: 10.1113/expphysiol.2012.071365

Alva, N., Palomeque, J., and Carbonell, T. (2013b). Oxidative stress and antioxidant activity in hypothermia and rewarming: can RONS modulate the beneficial effects of therapeutic hypothermia? Oxid. Med. Cell. Longev. 2013:957054. doi: 10.1155/2013/957054

Amoh, Y., Yang, M., Li, L., Reynoso, J., Bouvet, M., Moossa, A. R., et al. (2005). Nestin-linked green fluorescent protein transgenic nude mouse for imaging human tumor angiogenesis. Cancer Res. 65, 5352-5357. doi: 10.1158/0008-5472.CAN-05-0821

Birbrair, A., Zhang, T., Wang, Z. M., Messi, M. L., Olson, J. D., Mintz, A., et al. (2014). Type-2 pericytes participate in normal and tumoral angiogenesis. Am. J. Physiol. Cell Physiol. 307, C25-38. doi: 10.1152/ajpcell.00084.2014

Canale, S. T., Cantler, E. D. Jr., Sisk, T. D., and Freeman, B. L. III (1981). A chronicle of injuries of an American intercollegiate football team. Am. J. Sports Med. 9, 384-389. doi: 10.1177/036354658100900608

Carvalho, N., Puntel, G., Correa, P., Gubert, P., Amaral, G., Morais, J., et al. (2010). Protective effects of therapeutic cold and heat against the oxidative damage induced by a muscle strain injury in rats. J. Sports Sci. 28, 923-935. doi: 10.1080/02640414.2010.481722

Ceafalan, L. C., Manole, E., Tanase, C. P., Codrici, E., Mihai, S., Gonzalez, A., et al. (2015). Interstitial outburst of angiogenic factors during skeletal muscle regeneration after acute mechanical trauma. Anat. Rec. 298, 1864-1879. doi: 10.1002/ar.23254

Christov, C., Chretien, F., Abou-Khalil, R., Bassez, G., Vallet, G., Authier, F. J., et al. (2007). Muscle satellite cells and endothelial cells: close neighbors and privileged partners. Mol. Biol. Cell 18, 1397-1409. doi: 10.1091/mbc.E06-08-0693

Cizkova, D., Soukup, T., and Mokry, J. (2009a). Expression of nestin, desmin and vimentin in intact and regenerating muscle spindles of rat hind limb skeletal muscles. Histochem. Cell Biol. 131, 197-206. doi: 10.1007/s00418-008-0523-7

Cizkova, D., Soukup, T., and Mokry, J. (2009b). Nestin expression reflects formation, revascularization and reinnervation of new myofibers in regenerating rat hind limb skeletal muscles. Cells Tissues Organs (Print). 189, 338-347. doi: 10.1159/000142161

Coassin, M., Duncan, K. G., Bailey, K. R., Singh, A., and Schwartz, D. M. (2010). Hypothermia reduces secretion of vascular endothelial growth factor by cultured retinal pigment epithelial cells. Br. J. Ophthalmol. 94, 1678-1683. doi: $10.1136 /$ bjo.2009.168864

Dede, S., Deger, Y., and Meral, I. (2002). Effect of short-term hypothermia on lipid peroxidation and antioxidant enzyme activity in rats. J. Vet. Med. A Physiol. Pathol. Clin. Med. 49, 286-288. doi: 10.1046/j.1439-0442.2002. 00449.x

Dement, J. M., and Lipscomb, H. (1999). Workers' compensation experience of North Carolina residential construction workers, 1986-1994. Appl. Occup. Environ. Hyg. 14, 97-106. doi: 10.1080/104732299303269

Duvall, C. L., Taylor, W. R., Weiss, D., and Guldberg, R. E. (2004). Quantitative microcomputed tomography analysis of collateral vessel development after ischemic injury. Am. J. Physiol. Heart Circ. Physiol. 287, H302-H310. doi: 10.1152/ajpheart.00928.2003

Enns, D. L., and Tiidus, P. M. (2010). The influence of estrogen on skeletal muscle: sex matters. Sports Med. 40, 41-58. doi: 10.2165/11319760-000000000-00000

Fujino, H., Kohzuki, H., Takeda, I., Kiyooka, T., Miyasaka, T., Mohri, S., et al. (2005). Regression of capillary network in atrophied soleus muscle induced by hindlimb unweighting. J. Appl. Physiol. 98, 1407-1413. doi: 10.1152/japplphysiol.00961.2004

Gao, X. Y., Huang, J. O., Hu, Y. F., Gu, Y., Zhu, S. Z., Huang, K. B., et al. (2014). Combination of mild hypothermia with neuroprotectants has greater neuroprotective effects during oxygen-glucose deprivation and reoxygenationmediated neuronal injury. Sci. Rep. 4:7091. doi: 10.1038/srep07091

Gao, X. Y., Zhu, S. Z., Xiang, W., Huang, K. B., Hu, Y. F., Gu, Y., et al. (2016). Prolonged hypothermia exposure diminishes neuroprotection for severe ischemic-hypoxic primary neurons. Cryobiology 72, 141-147. doi: $10.1016 /$ j.cryobiol.2016.01.003
Haddix, T. L., Pohlman, T. H., Noel, R. F., Sato, T. T., Boyle, E. M. Jr., and Verrier, E. D. (1996). Hypothermia inhibits human E-selectin transcription. J. Surg. Res. 64, 176-183. doi: 10.1006/jsre.1996.0325

Hasegawa, M., Ogihara, T., Tamai, H., and Hiroi, M. (2009). Hypothermic inhibition of apoptotic pathways for combined neurotoxicity of iron and ascorbic acid in differentiated PC12 cells: reduction of oxidative stress and maintenance of the glutathione redox state. Brain Res. 1283, 1-13. doi: 10.1016/j.brainres.2009.06.016

Hershey, J. C., Baskin, E. P., Corcoran, H. A., Bett, A., Dougherty, N. M., Gilberto, D. B., et al. (2003). Vascular endothelial growth factor stimulates angiogenesis without improving collateral blood flow following hindlimb ischemia in rabbits. Heart Vessels 18, 142-149. doi: 10.1007/s00380-003-0694-z

Hershey, J. C., Baskin, E. P., Glass, J. D., Hartman, H. A., Gilberto, D. B., Rogers, I. T., et al. (2001). Revascularization in the rabbit hindlimb: dissociation between capillary sprouting and arteriogenesis. Cardiovasc. Res. 49, 618-625. doi: 10.1016/S0008-6363(00)00232-7

Ho, T. K., Rajkumar, V., Black, C. M., Abraham, D. J., and Baker, D. M. (2006). Increased angiogenic response but deficient arteriolization and abnormal microvessel ultrastructure in critical leg ischaemia. Br. J. Surg. 93, 1368-1376. doi: 10.1002/bjs.5496

Hollemann, D., Budka, H., Loscher, W. N., Yanagida, G., Fischer, M. B., and Wanschitz, J. V. (2008). Endothelial and myogenic differentiation of hematopoietic progenitor cells in inflammatory myopathies. J. Neuropathol. Exp. Neurol. 67, 711-719. doi: 10.1097/NEN.0b013e31817d8064

Horiguchi, T., Shimizu, K., Ogino, M., Suga, S., Inamasu, J., and Kawase, T. (2003). Postischemic hypothermia inhibits the generation of hydroxyl radical following transient forebrain ischemia in rats. J. Neurotrauma 20, 511-520. doi: 10.1089/089771503765355577

Huey, K. A., Smith, S. A., Sulaeman, A., and Breen, E. C. (2016). Skeletal myofiber VEGF is necessary for myogenic and contractile adaptations to functional overload of the plantaris in adult mice. J. Appl. Physiol. 120, 188-195. doi: 10.1152/japplphysiol.00638.2015

Inamasu, J., Suga, S., Sato, S., Horiguchi, T., Akaji, K., Mayanagi, K., et al. (2001). Intra-ischemic hypothermia attenuates intercellular adhesion molecule-1 (ICAM-1) and migration of neutrophil. Neurol. Res. 23, 105-111. doi: $10.1179 / 016164101101198217$

Ito, W. D., Arras, M., Scholz, D., Winkler, B., Htun, P., and Schaper, W. (1997). Angiogenesis but not collateral growth is associated with ischemia after femoral artery occlusion. Am. J. Physiol. 273, H1255-H1265.

Jarvinen, T. A., Jarvinen, T. L., Kaariainen, M., Kalimo, H., and Jarvinen, M. (2005). Muscle injuries: biology and treatment. Am. J. Sports Med. 33, 745-764. doi: $10.1177 / 0363546505274714$

Kao, C. H., Chio, C. C., Lin, M. T., and Yeh, C. H. (2011). Body cooling ameliorating spinal cord injury may be neurogenesis-, antiinflammation- and angiogenesis-associated in rats. J. Trauma 70, 885-893. doi: 10.1097/TA.0b013e3181e7456d

Kary, J. M. (2010). Diagnosis and management of quadriceps strains and contusions. Curr. Rev. Musculoskelet. Med. 3, 26-31. doi: 10.1007/s12178-010-9064-5

Kuo, J. R., Lo, C. J., Chang, C. P., Lin, H. J., Lin, M. T., and Chio, C. C. (2010). Brain cooling-stimulated angiogenesis and neurogenesis attenuated traumatic brain injury in rats. J. Trauma 69, 1467-1472. doi: 10.1097/TA.0b013e3181f31b06

Lee, H., Natsui, H., Akimoto, T., Yanagi, K., Ohshima, N., and Kono, I. (2005). Effects of cryotherapy after contusion using realtime intravital microscopy. Med. Sci. Sports Exerc. 37, 1093-1098. doi: 10.1249/01.mss.0000169611.21671.2e

Li, Q. F., Wang, X. R., Yang, Y. W., and Su, D. S. (2006). Up-regulation of hypoxia inducible factor 1alpha by isoflurane in Hep3B cells. Anesthesiology 105, 1211-1219. doi: 10.1097/00000542-200612000-00021

Luk, K., Boatman, S., Johnson, K. N., Dudek, O. A., Ristau, N., Vang, D., et al. (2012). Influence of morphine on pericyte-endothelial interaction: implications for antiangiogenic therapy. J. Oncol. 2012:458385. doi: 10.1155/2012/458385

Lv, O., Zhou, F., Zheng, Y., Li, Q., Wang, J., and Zhu, Y. (2016). Mild hypothermia protects against early brain injury in rats following subarachnoid hemorrhage via the TrkB/ERK/CREB signaling pathway. Mol. Med. Rep. 14, 3901-3907. doi: 10.3892/mmr.2016.5709

Maier, C. M., Sun, G. H., Cheng, D., Yenari, M. A., Chan, P. H., and Steinberg, G. K. (2002). Effects of mild hypothermia on superoxide anion production, 
superoxide dismutase expression, and activity following transient focal cerebral ischemia. Neurobiol. Dis. 11, 28-42. doi: 10.1006/nbdi.2002.0513

Meeusen, R., and Lievens, P. (1986). The use of cryotherapy in sports injuries. Sports Med. 3, 398-414. doi: 10.2165/00007256-198603060-00002

Merrick, M. A., Rankin, J. M., Andres, F. A., and Hinman, C. L. (1999). A preliminary examination of cryotherapy and secondary injury in skeletal muscle. Med. Sci. Sports Exerc. 31, 1516-1521. doi: 10.1097/00005768-199911000-00004

Miyazaki, D., Nakamura, A., Fukushima, K., Yoshida, K., Takeda, S., and Ikeda, S. (2011). Matrix metalloproteinase-2 ablation in dystrophin-deficient $\mathrm{mdx}$ muscles reduces angiogenesis resulting in impaired growth of regenerated muscle fibers. Hum. Mol. Genet. 20, 1787-1799. doi: 10.1093/hmg/ddr062

Mokry, J., Cizkova, D., Filip, S., Ehrmann, J., Osterreicher, J., Kolar, Z., et al. (2004). Nestin expression by newly formed human blood vessels. Stem Cells Dev. 13, 658-664. doi: 10.1089/scd.2004.13.658

Niiyama, T., Higuchi, I., Hashiguchi, T., Suehara, M., Uchida, Y., Horikiri, T., et al. (2003). Capillary changes in skeletal muscle of patients with Ullrich's disease with collagen VI deficiency. Acta Neuropathol. 106, 137-142. doi: 10.1007/s00401-003-0714-1

Novak, M. L., Bryer, S. C., Cheng, M., Nguyen, M. H., Conley, K. L., Cunningham, A. K., et al. (2011). Macrophage-specific expression of urokinasetype plasminogen activator promotes skeletal muscle regeneration. J. Immunol. 187, 1448-1457. doi: 10.4049/jimmunol.1004091

Ochoa, O., Sun, D., Reyes-Reyna, S. M., Waite, L. L., Michalek, J. E., McManus, L. M., et al. (2007). Delayed angiogenesis and VEGF production in CCR2-/mice during impaired skeletal muscle regeneration. Am. J. Physiol. Regul. Integr. Comp. Physiol. 293, R651-R661. doi: 10.1152/ajpregu.00069.2007

Osterman, A. L., Heppenstall, R. B., Sapega, A. A., Katz, M., Chance, B., and Sokolow, D. (1984). Muscle ischemia and hypothermia: a bioenergetic study using 31P nuclear magnetic resonance spectroscopy. J. Trauma 24, 811-817. doi: 10.1097/00005373-198409000-00006

Puntel, G. O., Carvalho, N. R., Amaral, G. P., Lobato, L. D., Silveira, S. O., Daubermann, M. F., et al. (2011). Therapeutic cold: an effective kind to modulate the oxidative damage resulting of a skeletal muscle contusion. Free Radic. Res. 45, 125-138. doi: 10.3109/10715762.2010.517252

Qu, Z., Andersen, J. L., and Zhou, S. (1997). Visualisation of capillaries in human skeletal muscle. Histochem. Cell Biol. 107, 169-174. doi: $10.1007 / \mathrm{s} 004180050101$

Rauen, U., and de Groot, H. (2002). Mammalian cell injury induced by hypothermia- the emerging role for reactive oxygen species. Biol. Chem. 383, 477-488. doi: 10.1515/BC.2002.050

Rhoads, R. P., Johnson, R. M., Rathbone, C. R., Liu, X., Temm-Grove, C., Sheehan, S. M., et al. (2009). Satellite cell-mediated angiogenesis in vitro coincides with a functional hypoxia-inducible factor pathway. Am. J. Physiol. Cell Physiol. 296, C1321-C1328. doi: 10.1152/ajpcell.00391.2008

Saito, Y., Nakagami, H., Azuma, N., Hirata, S., Sanada, F., Taniyama, Y., et al. (2011). Critical roles of cold shock domain protein A as an endogenous angiogenesis inhibitor in skeletal muscle. Antioxid. Redox Signal. 15, 2109-2120. doi: 10.1089/ars.2010.3714

Sapega, A. A., Heppenstall, R. B., Sokolow, D. P., Graham, T. J., Maris, J. M., Ghosh, A. K., et al. (1988). The bioenergetics of preservation of limbs before replantation. The rationale for intermediate hypothermia. J. Bone Joint Surg. Am. 70, 1500-1513. doi: 10.2106/00004623-198870100-00010

Schaser, K. D., Disch, A. C., Stover, J. F., Lauffer, A., Bail, H. J., and Mittlmeier, T. (2007). Prolonged superficial local cryotherapy attenuates microcirculatory impairment, regional inflammation, and muscle necrosis after closed soft tissue injury in rats. Am. J. Sports Med. 35, 93-102. doi: 10.1177/0363546506294569

Schaser, K. D., Stover, J. F., Melcher, I., Lauffer, A., Haas, N. P., Bail, H. J., et al. (2006). Local cooling restores microcirculatory hemodynamics after closed soft-tissue trauma in rats. J. Trauma 61, 642-649. doi: 10.1097/01.ta.0000174922.08781.2f

Singleton, P. A., Lingen, M. W., Fekete, M. J., Garcia, J. G., and Moss, J. (2006). Methylnaltrexone inhibits opiate and VEGF-induced angiogenesis: role of receptor transactivation. Microvasc. Res. 72, 3-11. doi: 10.1016/j.mvr.2006.04.004

Stratton, S. A., Heckmann, R., and Francis, R. S. (1984). Therapeutic ultrasound: its effects on the integrity of a nonpenetrating wound. J. Orthop. Sports Phys. Ther. 5, 278-281. doi: 10.2519/jospt.1984.5.5.278
Summan, M., Warren, G. L., Mercer, R. R., Chapman, R., Hulderman, T., Van Rooijen, N., et al. (2006). Macrophages and skeletal muscle regeneration: a clodronate-containing liposome depletion study. Am. J. Physiol. Regul. Integr. Comp. Physiol. 290, R1488-R1495. doi: 10.1152/ajpregu.00465.2005

Sun, W., Wang, Z., Cao, J., Cui, H., and Ma, Z. (2016). Cold stress increases reactive oxygen species formation via TRPA1 activation in A549 cells. Cell Stress Chaperones 21, 367-372. doi: 10.1007/s12192-015-0663-3

Swenson, C., Sward, L., and Karlsson, J. (1996). Cryotherapy in sports medicine. Scand. J. Med. Sci. Sports 6, 193-200. doi: 10.1111/j.1600-0838.1996.tb 00090.x

Takagi, R., Fujita, N., Arakawa, T., Kawada, S., Ishii, N., and Miki, A. (2011). Influence of icing on muscle regeneration after crush injury to skeletal muscles in rats. J. Appl. Physiol. 110, 382-388. doi: 10.1152/japplphysiol.0118 7.2010

Takeyama, M., Yoneda, M., Gosho, M., Iwaki, M., and Zako, M. (2015). Decreased VEGF-A and sustained PEDF expression in a human retinal pigment epithelium cell line cultured under hypothermia. Biol. Res. 48:42. doi: 10.1186/s40659-015-0034-7

Tanaka, T., Wakamatsu, T., Daijo, H., Oda, S., Kai, S., Adachi, T., et al. (2010). Persisting mild hypothermia suppresses hypoxia-inducible factorlalpha protein synthesis and hypoxia-inducible factor-1-mediated gene expression. Am. J. Physiol. Regul. Integr. Comp. Physiol. 298, R661-R671. doi: 10.1152/ajpregu.00732.2009

Teixeira, C. F., Zamuner, S. R., Zuliani, J. P., Fernandes, C. M., Cruz-Hofling, M. A., Fernandes, I., et al. (2003). Neutrophils do not contribute to local tissue damage, but play a key role in skeletal muscle regeneration, in mice injected with Bothrops asper snake venom. Muscle Nerve 28, 449-459. doi: 10.1002/mus.10453

Vaittinen, S., Lukka, R., Sahlgren, C., Hurme, T., Rantanen, J., Lendahl, U., et al. (2001). The expression of intermediate filament protein nestin as related to vimentin and desmin in regenerating skeletal muscle. J. Neuropathol. Exp. Neurol. 60, 588-597. doi: 10.1093/jnen/60.6.588

Vieira Ramos, G., Pinheiro, C., Messa, S., Delfino, G., de Cassia Marqueti, R., de Fatima Salvini, T., et al. (2016). Cryotherapy reduces inflammatory response without altering muscle regeneration process and extracellular matrix remodeling of rat muscle. Sci. Rep. 6:18525. doi: 10.1038/srep18525

Volpi, P., Melegati, G., Tornese, D., and Bandi, M. (2004). Muscle strains in soccer: a five-year survey of an Italian major league team. Knee Surg. Sports Traumatol. Arthrosc. 12, 482-485. doi: 10.1007/s00167-003-0478-0

Wagatsuma, A. (2007). Endogenous expression of angiogenesis-related factors in response to muscle injury. Mol. Cell. Biochem. 298, 151-159. doi: 10.1007/s11010-006-9361-x

Wiik, A., Ekman, M., Morgan, G., Johansson, O., Jansson, E., and Esbjornsson, M. (2005). Oestrogen receptor beta is present in both muscle fibres and endothelial cells within human skeletal muscle tissue. Histochem. Cell Biol. 124, 161-165. doi: 10.1007/s00418-005-0030-z

Zuo, L., and Clanton, T. L. (2005). Reactive oxygen species formation in the transition to hypoxia in skeletal muscle. Am. J. Physiol. Cell Physiol. 289, C207-C216. doi: 10.1152/ajpcell.00449.2004

Zuo, L., Roberts, W., Tolomello, R., and Goins, A. (2013a). Ischemic and hypoxic preconditioning protect cardiac muscles via intracellular ROS signaling. Front. Biol. 8, 305-311. doi: 10.1007/s11515-012-1225-Z

Zuo, L., Shiah, A., Roberts, W. J., Chien, M. T., Wagner, P. D., and Hogan, M. C. (2013b). Low $\mathrm{PO}_{2}$ conditions induce reactive oxygen species formation during contractions in single skeletal muscle fibers. Am. J. Physiol. Regul. Integr. Comp. Physiol. 304, R1009-R1016. doi: 10.1152/ajpregu.00563.2012

Conflict of Interest Statement: The authors declare that the research was conducted in the absence of any commercial or financial relationships that could be construed as a potential conflict of interest.

Copyright (c) 2017 Singh, Barani Lonbani, Woodruff, Parker, Steck and Peake. This is an open-access article distributed under the terms of the Creative Commons Attribution License (CC BY). The use, distribution or reproduction in other forums is permitted, provided the original author(s) or licensor are credited and that the original publication in this journal is cited, in accordance with accepted academic practice. No use, distribution or reproduction is permitted which does not comply with these terms. 